diversity and protect human health; they should not be designed to discriminate against GM crops.

Furthermore, GM critics are wrong to conclude that because biotechnology does not solve all problems, it has no place in helping humanity to address long-term food needs. They often base their arguments on the presumption that most of the unintended consequences of genetic modification are likely to be negative, such as cases in which herbicide-resistant crops have spread to neighbouring lands. But we must look at the relative risks of all technologies, including the risks of not adopting the technology - such as how African nations would have suffered without the Green Revolution. According to a 2010 European Commission report on GM organisms, A Decade of EU-Funded GMO Research, based on 130 research projects spanning more than 25 years and involving more than 500 independent research groups, "biotechnology, and in particular GMOs, are not per se more risky than e.g. conventional plant breeding technologies".

The application of biotechnology has a number of unintended ecological benefits. For example, the adoption of GM crops has curbed the release of greenhouse-gas emissions by reducing the use of pesticides, which require energy to manufacture. It has also saved farmers from heavy exposure to these chemicals. In addition, the use of herbicide-tolerant crops enables farmers to cut back on the ploughing and weeding that releases carbon that would otherwise be sequestered in the soil. For 2009, it is estimated that biotech crops resulted in 17.6 billion kilograms of carbon dioxide sequestration and forgone release - the equivalent of removing 7.8 million cars from the road.

Solving world hunger will involve more than just producing more food. But excluding technological options that raise productivity will do more harm than good. The international community would be better served by taking a pragmatic approach that accommodates the best available technological options, rather than relying on ideological political positions that will put the world's most vulnerable people at risk. All technological options for meeting global food needs should therefore be on the table, including agricultural biotechnology.

Calestous Juma is the director of the Agricultural Innovation in Africa Project at Harvard Kennedy School, Cambridge, Massachusetts 02138, USA. He is author of The New Harvest: Agricultural Innovation in Africa (Oxford Univ. Press, 2011).

e-mail: calestous_juma@harvard.edu

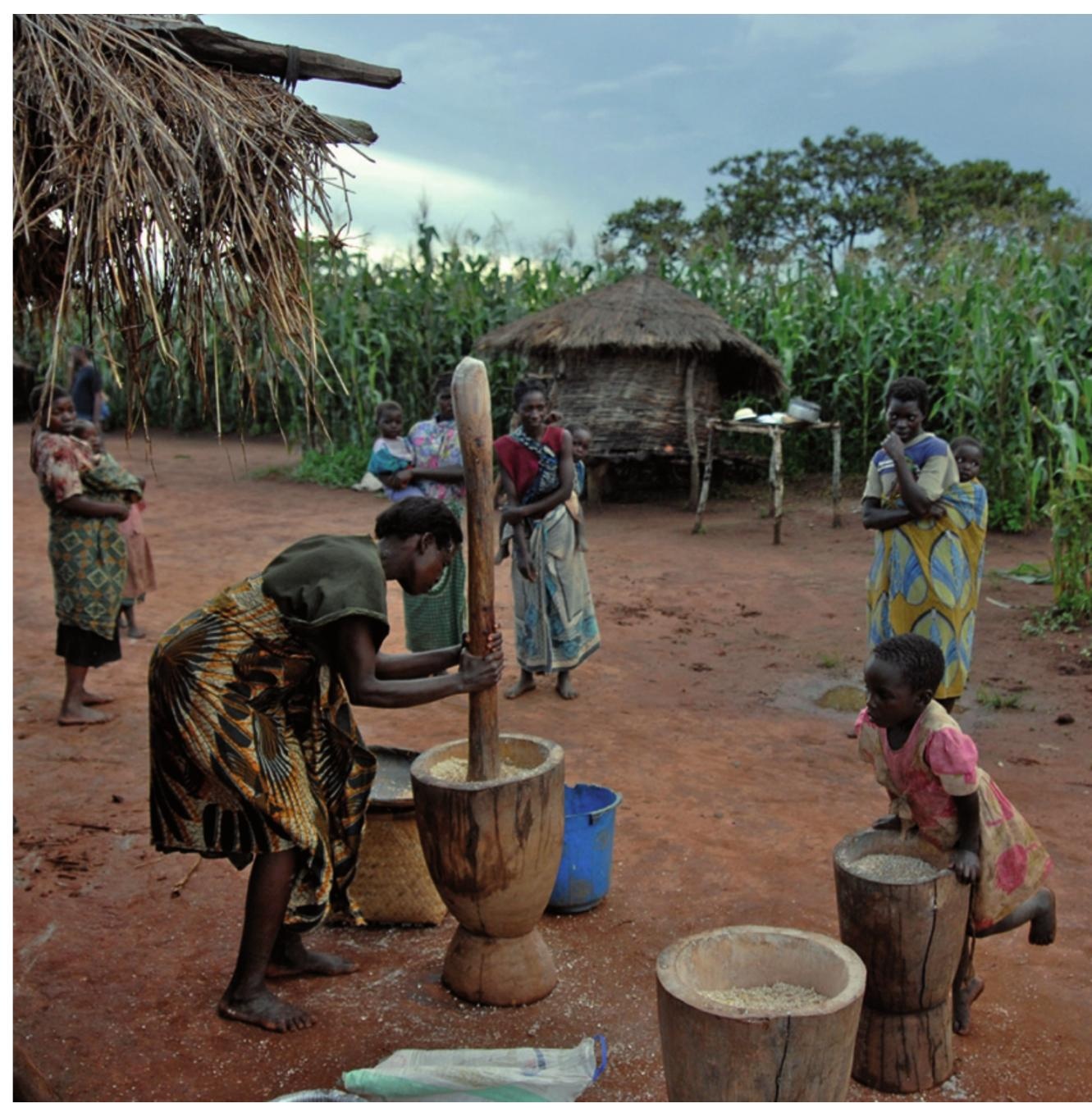

Giving power back to the people is key to ensuring the security of food supplies.

\title{
Preventing hunger: Change economic policy
}

Simply giving people food is not enough to prevent famine, says Peter Rosset. Instead, we need to overhaul the policies that have upended the food supply.

$\mathrm{T}$ The global food system is broken. The number of hungry and undernourished people in the world hovers at around 1 billion $^{1}$ and the past few years have seen both worldwide food riots as well as epidemics of obesity and diabetes.

Fifty years ago, the United Nations World Food Programme was formed to help reduce hunger. But its original mandate of handing out food was a band-aid at best - and can actually make people more vulnerable to hunger. We now have a food system that has been destroyed by decades of misguided policies that emphasized exports over feeding domestic populations and by runaway financial speculation. We now need to reverse those policies and fix what's broken.

According to the economic law of comparative advantage, agribusinesses should export the food, agrofuels and other products that are grown in a country, while cheaper foods are imported to feed the people. Any gaps in such a 'productionist' and 'free trade' system should then be covered by food aid, in which organizations such as the US Agency for International Development (USAID) and the World Food Programme 
purchase surpluses from some countries to donate to the poor in others.

But in reality, such a system exacerbates rather than alleviates hunger. When agribusinesses use land in poor countries for exports, local food producers are driven off and poor consumers become dependent on imports to feed themselves.

At a global scale, hunger is not the result of insufficient food. Although per capita food production has climbed steadily for decades, food prices have become very volatile (see 'Roots of hunger'). And when food prices go up, so does the number of hungry people.

\section{SO WHY THE VOLATILITY IN FOOD PRICES?}

First, in most countries the past three decades of neoliberal economic policy have resulted in the cutting back of support for people who produce food for domestic markets ${ }^{2}$. These policies also forced public sectors to downsize their food reserves and stop buying food to stockpile against famine. This meant that the small farmers lost a key buyer and their guarantee of minimally acceptable crop prices $^{3}$, so they began to produce less food for local populations.

Because most of the global food reserves have been deregulated and are now controlled by the private sector, outside investors can buy and sell food in the same way that they speculate in gold or oil. Speculative cash now floods in and out, and when it comes in, food prices jump beyond the reach of the poor. Speculators can also bet on whether food prices will rise or fall on the futures market, further driving price volatility ${ }^{4}$. Such practices have grown dramatically since the US housing bubble burst in 2007-08, which prompted investors to seek new markets. That period alone saw US $\$ 200$ billion more speculative capital injected into food futures markets than any previous year ${ }^{5}$.

During this time, the prospect of agrofuels drew even more investors and caused food prices to spike 6 . A global 30\% rise in maize (corn) prices, for example, prompted the private-sector companies in various countries to hoard supplies while investors speculated on the price at the national level. This caused the infamous 'tortilla crisis' in Mexico, where the multinational food trader Cargill withheld maize from the national market. The hoarding and resultant speculation transformed a $30 \%$ hike on global markets into a $300 \%$ price jump for domestic consumers.

If we seriously want to address hunger, we can't rely just on food handouts: they enable countries to continue exporting and importing food rather than helping local farmers to feed their populations over the long term. Furthermore, food aid will not change the policies that have pushed production into agribusiness hands and promoted exports. The current trade regime only exacerbates the situation. Instead of further deregulating and globalizing the food system, we need to return it to national control.

The main alternative policy, called food sovereignty, was initially put forth by La Via Campesina ${ }^{7}$ - a global movement that brings together peasants and family farmers from around the world - but has since been taken up by numerous governments and UN agencies. The basic idea is to identify and address the key ills of the food system directly to guarantee healthy, affordable, locally produced food for everyone.

The shifting of productive capacity away from domestic food markets and towards exports has to be reversed. So-called 'fair trade', in which wealthy-country consumers pay a bit more for coffee or bananas with a fair trade label doesn't come close to tackling the problem. Instead, structural changes are needed that support the family farmers and peasants who still produce more than $70 \%$ of the world's food. These people need access to land, which means putting an end to the current global frenzy of corporate land grabbing, and implementing genuine land reforms ${ }^{2}$. They need fair prices and secure access to their local and national markets. This means a step back from trade deregulation, and the restoration of price-support

\section{ROOTS OF HUNGER}

Never before has so much food been available per person (top), yet prices fluctuate wildly (middle) and hunger persists (bottom).

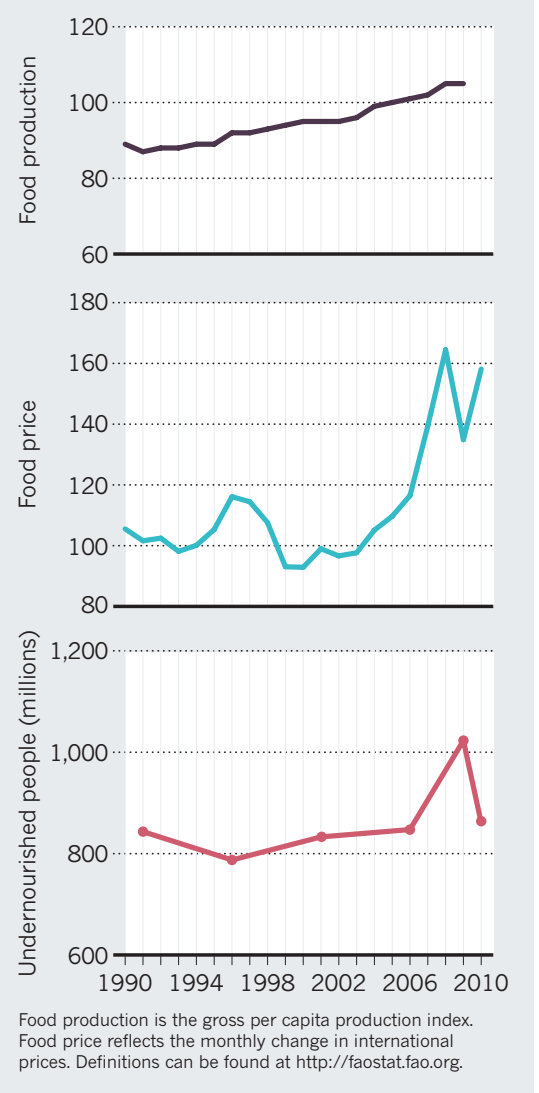

mechanisms ${ }^{3}$ that help small farmers to cover the cost of production and live their lives with dignity.

Food reserves must be taken back from private-sector hoarders and speculators. Although government food agencies have been plagued by corruption and inefficiency, eliminating them has been worse.

"Speculation
onfood
markets
has grown
dramatically
since the
US housing
bubble burst."

A new system should include transparent co-ownership and co-management between the public sector, farmer and consumer organizations $^{3}$. At the international level, we need effective governance mechanisms to keep speculative funds out of the food economy and to apply anti-monopoly measures ${ }^{3}$.

Finally, we need to take a hard look at some of our most cherished assumptions. Contrary to popular belief, small farmers tend to be more productive per unit area and use fewer agrochemicals than large corporate farmers do because they have integrated farms that combine multiple crops with livestock ${ }^{8}$. A lot more food could therefore be produced using ecological farming techniques and on smaller farms ${ }^{9}$. This would not only break the link between petroleum and rising foodproduction costs, it would also offer more resiliency to climate change and contribute less to global warming than the conventional dependence on fertilizer, pesticides and genetically modified organisms ${ }^{10}$.

The actions of humanitarian agencies such as the World Food Programme have little or no effect on the causes of hunger. What we urgently need are structural changes in the damaging economic policies that create food crises.

Peter M. Rosset is a researcher at the Center for the Study of Rural Change in Mexico (CECCAM) and a visiting research scientist at the University of Michigan in Ann Arbor. e-mail: rosset@globalalternatives.org

1. Food and Agriculture Organization of the United Nations The State of Food Insecurity in the World 2011 (FAO, 2011).

2. Rosset, P. Development 54, 21-30 (2011).

3. Rosset, P. M. Food is Different (Zed, 2006).

4. de Schutter, O. Food commodities speculation and food price crises. Briefing Note 02:1-14 (United Nations, 2010).

5. Ghosh, J. J. Agrarian Change 10, 72-86 (2010).

6. Rosset, P. M. Bull. Sci. Technol. Soc. 29, 189-193 (2009).

7. Martínez-Torres, M. E. \& Rosset, P. M. J. Peasant Stud. 37, 149-175 (2010).

8. Rosset, P. M. The multiple functions and benefits of small farm agriculture. Food First Policy Brief 4 , 1-22 (Institute for Food and Development Policy, 1999).

9. Badgley, C. et al. Renew. Agri. Food Syst. 22, 86-108 (2007).

10.Rosset, P. M. et al. J. Peasant Stud. 38, 161-191 (2011). 